\title{
CELARI ONLINE: NOVO MEIO TECNOLÓGICO DE AULAS PARA IDOSOS - CARACTERÍSTICAS SOCIODEMOGRÁFICAS E ADESÃO
}

Priscilla Cardoso da Silva'; PPGCMH/UFRGS; priscilla.cardoso@ufrgs.br; Débora Pastoriza Sant' Helena'; PPGCMH/UFRGS; deborapsh24@gmail.com; Luciane Job Junqueira dos Santos²; UFRGS; luciane.job.74@gmail.com; Ruane Cardoso Nolasco²; UFRGS; ruanenolasco@gmail.com; Andréa Gonçalves Kruger; PPGCMH/ UFRGS; andreakgoncalves@gmail.com.

\section{RESUMO}

Introdução: Com o surgimento da pandemia (COVID-19) ocorreram modificações no estilo de vida e realização de atividades, principalmente entre os idosos por serem do grupo de risco. O programa de extensão Centro de Estudo de Lazer e Atividade Física do Idoso (CELARI) adaptou suas atividades presenciais para online utilizando a tecnologia como um recurso promissor para prática de atividade física. Objetivo: Investigar a caracterização sociodemográfica e a adesão ao exercício físico online de idosos no programa de extensão CELARI na pandemia. Método: Estudo cross-sectional com atividades de exercício físico online (plataforma Facebook) três vezes por semana. A amostra por acessibilidade com média de idade 72,25 $\pm 6,38$ anos. Utilizou-se questionário sócio-demográfico e ficha de frequência (1a a 46 aula), estatística descritiva (SPSS20.0) (Comitê de Ética n⿳021.629). Resultados: Dos 162 idosos do programa que adotaram a plataforma, 103 (63,6\%) participaram das aulas online; 94,2\% são mulheres, $43,7 \%$ casadas, $75,7 \%$ possuem ensino médio, $78,6 \%$ são aposentadas e $44,7 \%$ moram com o cônjuge. A média de participação das aulas foi de $33,73 \pm 12,80$; destes $11 \%$ frequentou 13 aulas, $11 \%$ de 14 a 22 aulas, $13 \%$ de 23 a 32 aulas, $29 \%$ de 32 a 41 aulas e $36 \%$ participaram de $\geq 41$ aulas. Os motivos de adesão às aulas foram a aproximação social, bem estar mental e se manter ativo. Conclusão: Estudo mostrou que os idosos se adaptaram ao novo recurso tecnológico, buscando através das aulas online um meio de manter a interação social e o exercício físico durante a pandemia.

Palavras-chave: Idoso; COVID-19; Exercício físico; Aula.

Agradecimento: O apoio a Coordenação de Aperfeiçoamento de Pessoal de Nível Superior- Brasil (CAPES) ${ }^{1}$ - Código de Financiamento 001, e ao Programa de Bolsa de Extensão Universitária (PROREXT/UFRGS) ${ }^{2}$. 